\title{
La extracción de la piedra de la locura: una visión neuroquirúrgica
}

\author{
The extraction of the stone of madness: a neurosurgical vision
}

José Luis Alcocer Maldonado*

Citar como: Alcocer MJL. La extracción de la piedra de la locura: una visión neuroquirúrgica. Acta Med. 2021; 19 (1): 148-150. https://dx.doi.org/10.35366/98593

\section{Resumen}

Existen una serie de cuadros de pintores holandeses de los siglos XV y XVI que tratan de "La extracción de la piedra de la locura", siendo el más característico y conocido el pintado en 1480 por Hieronymus Bosch "El Bosco". El escrito surge del análisis de los múltiples comentarios que se han vertido sobre la misma por críticos del arte, psiquiatras, filólogos e historiadores del arte; de ahí la conveniencia de una visión neuroquirúrgica de este cuadro y varios relacionados que corresponden a la época.

Palabras clave: Extracción de la piedra de la locura, pintura flamenca, trepanación craneal, neurocirugía, magia y medicina, causas de locura.
Para entrar en materia, la obra pictórica denominada "La extracción de la piedra de la locura" es un óleo pintado sobre tabla de roble, sus dimensiones son $48 \times 35 \mathrm{~cm}$. Fue realizada entre 1475 y 1480 por el pintor holandés Hieronymus Bosch "El Bosco", ${ }^{1}$ y corresponde a su primera etapa. Actualmente, se encuentra en el Museo del Prado, se conoce toda su historia: inicialmente, perteneció a Felipe de Borgoña, obispo de Utrecht, hijo ilegítimo de Felipe III, el Bueno, el cual la mandó a hacer; fue vendido en 1529 a la colección real española de Felipe $\checkmark$, expuesta en la quinta del Duque de Arco por muchos

\footnotetext{
* Neurocirujano, Catedrático de la Facultad de Medicina de León, Universidad de Guanajuato. México.
}

Correspondencia:

Dr. José Luis Alcocer Maldonado

Correo electrónico: alcocermjl@hotmail.com

Aceptado: 23-11-2020.

www.medigraphic.com/actamedica

\section{Abstract}

There are a series of canvasses by Dutch painters from the 15th and 16th centuries that deal with "The extraction of the stone of madness", the most characteristic and well-known is the one painted in 1480 by Hieronymus Bosch "El Bosco". This writing arises from the analysis of the multiple comments that have been made on it by art critics, psychiatrists, philologists and art historians; hence the convenience of a neurosurgical view of this painting and several other ones contemporary to it.

Keywords: Extraction of the stone of madness, flemish painting, cranial trepanation, neurosurgery, magic and medicine, causes of insanity.

años, y finalmente pasó a ser propiedad del Museo del Prado a partir de $1839 .^{2}$

En cuanto al tema profano, fue inspirado en los escudos de armas de los duques de Borgoña. Representa en el centro un espejo, y en él se observa la sustracción de la cabeza del paciente de un nenúfar (planta acuática de hojas redondas u ovaladas, con grandes pecíolos, que flota en la superficie del agua y cuenta con flores olorosas, blancas, rosadas o amarillas), observándose otros dos sobre la mesa. El falso cirujano lleva un embudo en la cabeza lo cual muestra que es un timador. Un monje está a su lado con un jarro de cerveza en su mano. La mujer, monja o esposa, con un libro sobre la cabeza. El paciente se encuentra fijo de la cintura, no de las manos, con una expresión de tonto o lunático. A su lado se encuentra su bolso con dinero. Rodeando el espejo en negro y con letras góticas doradas dice así: "Meester snijt die keye ras, Mijne name is lubbert das" (Maestro, quítame pronto esta piedra, que yo me llamo Lubbert Das) (Figura 1). ${ }^{2}$

El cuadro presenta una técnica diferente a la comúnmente utilizada por el Bosco, ya que no se observan 


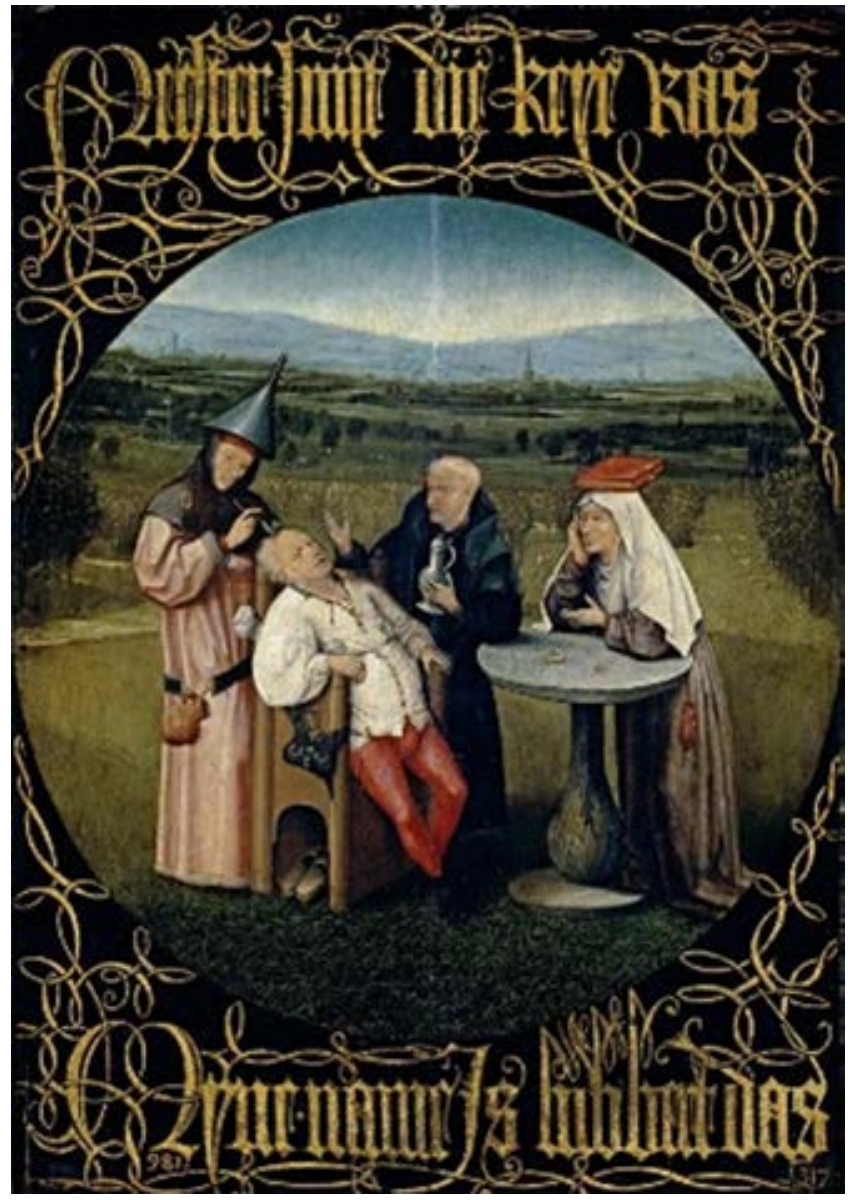

Figura 1: "La extracción de la piedra de la locura", realizada entre 1475 y 1480 por el pintor holandés Hieronymus Bosch "El Bosco". Actualmente en el Museo del Prado.

cambios o correcciones de los contornos. Existen múltiples interpretaciones sobre lo que representa, una de ellas expresa que la extirpación de la flor es una alusión a la lujuria.

El estudio iconográfico de la pintura muestra claramente que: el operador es un cirujano barbero, el cual no tiene preparación médica formal y está tratando a un paciente que sufre de locura. En el siglo XV se consideraba loco a toda persona con una actitud contraria a las reglas sociales establecidas. Existían tres tipos de locos: el primero lo constituían los pacientes que actualmente se clasifican como esquizofrénicos, bipolares con depresión profunda, los cuales se trataban con encierro o se embarcan en el barco de la locura; el segundo, formado por los pacientes con trastornos conductuales mínimos y deficiencias neurológicas; el tercero, formado por aquellos con trastornos en la esfera sexual: lujuria, impotencia y enamorados.
La implantación de un objeto como causa de enfermedad es una concepción primitiva mundial, la cual aún persiste en culturas de México en los estados de Chiapas y Oaxaca. El pensamiento de que la introducción del objeto, llámese: piedra, huesos, dientes, es origen de la enfermedad, junto con otras ideas mágico-religiosas, como son la introducción de un espíritu o la pérdida del alma, el cual se debe a un hechizo, explica en el modelo primitivo las causas de enfermedad, dando pie a que la terapéutica, para alcanzar la curación, debe practicarla un hechicero mediante acciones como la limpia, el soplido, o realizando escarificación y/o o succión en cualquier parte del cuerpo, requiriendo que la enfermedad que se ha extraído aparezca materializada en los más diversos objetos como: arenillas, piedras, espinas, semillas, gusanos, hormigas, etc. ${ }^{4}$

La remoción de objetos del cuerpo humano es una práctica común en la historia de la enfermedad, siendo una de las causas más común de los padecimientos. Un ejemplo claro de cómo funciona el concepto de extirpación de un objeto, se tiene en el caso del párroco Hernán Sánchez Bordiales, en el año 1624, en el pueblo de Quacomán, Michoacán, donde se relata: "Porque en hechizaste al padre siendo sacerdote, cúrale y quítale el hechizo de donde lo tiene". Y luego, tomó la india la pierna desnuda, comenzó a chupar, y en presencia de todos, sacó asido a los dientes un hueso largo de dos dedos de ancho y al padre curó. ${ }^{5}$

\section{VISIÓN NEUROQUIRÚRGICA}

Técnicamente, en ninguno de los cuadros que tratan de la extracción de la piedra de la locura se muestran trepanaciones, únicamente es la incisión en el cuero cabelludo y la extirpación del objeto (piedra o flores). La

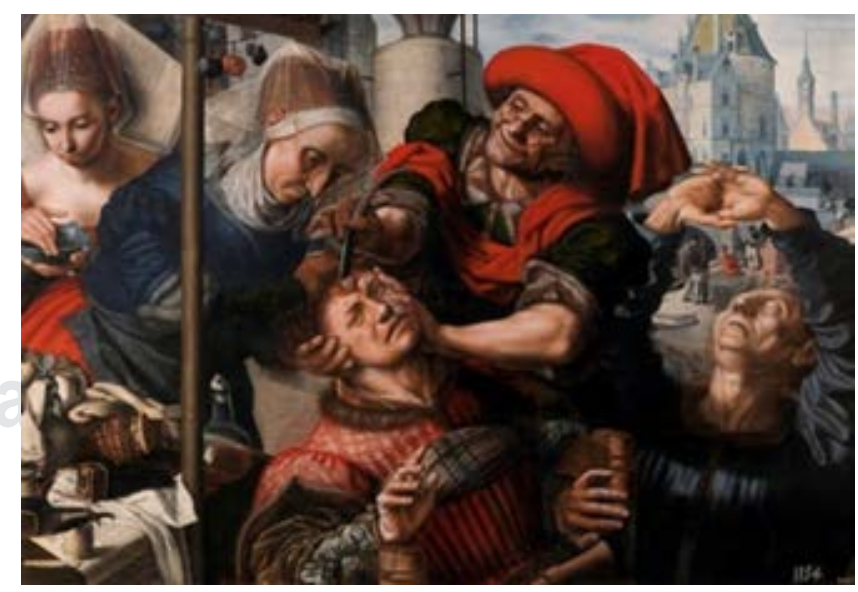

Figura 2: "El cirujano" o "La extracción de la piedra de la locura", realizada por Jan Sanders van Hemessen, entre 1550 y 1555. Museo del Prado. 


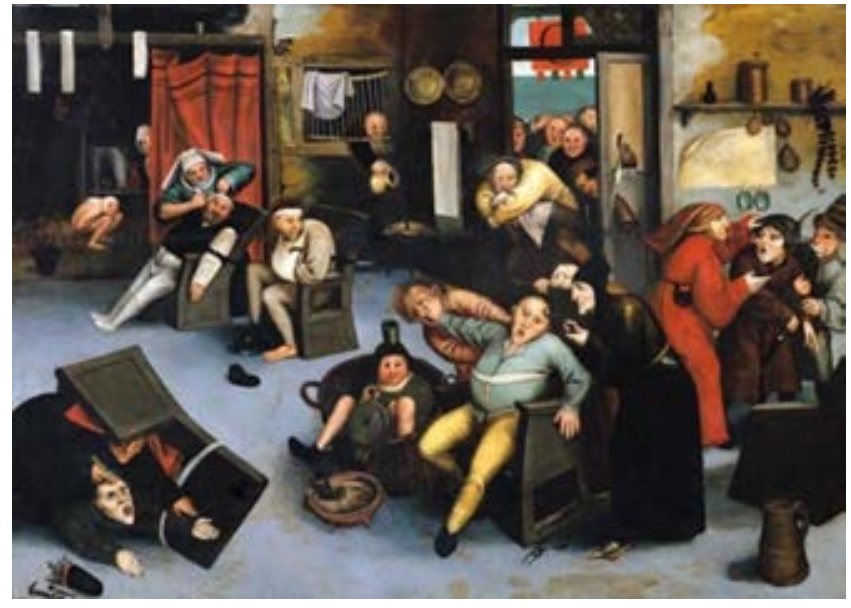

Figura 3: "La extracción de la piedra de la locura", realizada por Pieter Brueghel, llamado "el Viejo", en 1556. Musée de l'Hotel Sandelin (Saint-Omer, Francia). Se observan una serie de pacientes con trastornos psiquiátricos y su tratamiento practicándoles la extracción de la piedra de la locura.

trepanación es un procedimiento terapéutico practicado hace 8,000 años antes de esta era. Es el procedimiento quirúrgico más antiguo, como lo demuestran los diversos cráneos de muchas culturas. La causa de su práctica se encuentra con múltiples suposiciones. En el papiro de Edwin Smith se le indica como terapéutica para tratar las heridas de cráneo, mencionando por primera vez las palabras: líquido cefalorraquídeo, cerebro y retiro de fragmentos óseos hundidos. En el tratado quirúrgico de Hipócrates se refieren las instrucciones y manera de practicar los trépanos, siendo su principal indicación los traumatismos de cráneo.

Esta práctica continúo en Roma con Galeno; durante el renacimiento, los principales cirujanos de guerra practicaban trépanos para heridas traumáticas de cráneo. En el periodo en que se realizaron las pinturas del Bosco, existían cirujanos hábiles que ejercían esta praxis normalmente en campos de batalla, como ejemplo se tiene a Giovanni da Vigo (1450-1525) y el gran cirujano Ambroise Paré (15101590). Se debe aclarar que los cirujanos barberos en la edad media e inicios del renacimiento se dedicaban a practicar procedimientos como: las flebotomías, remoción de piezas dentarias y drenaje de abscesos, no tenían ni capacidad ni instrumental para realizar una trepanación. Es a partir del siglo XIX que se inicia el tratamiento de las patologías neurológicas no traumáticas como tumores, epilepsia y cirugía para dolor.

Existe una serie de pinturas europeas del siglo XV que tratan el tema de la extracción de la piedra de la locura, las cuales se muestran a continuación en orden cronológico.

\section{REFERENCIAS}

1. Boom H. El Bosco al desnudo. Madrid: A. Machado libros; 2016. pp. 1-216.

2. Büttner N. Hieronymus Bosch "El Bosco": visiones y pesadillas. México: Alianza editorial; 2016.

3. González HI. La piedra de la locura. Revista Digital de Iconografía Medieval. 2012; 4 (8): 79-88.

4. Foucault M. Historia de la locura en la época clásica. 3a ed. México: FCE; 2015.

5. Aguirre BG. Medicina y magia. El proceso de aculturación en la estructura colonial. México: Instituto Nacional Indigenista; 1963. 